\title{
Locomotion of commercial broilers and indigenous chickens
}

\section{Marília Carvalho Figueiredo Alves ${ }^{1}$, Ibiara Correia de Lima Almeida Paz ${ }^{2}$, Irenilza de Alencar Nääs ${ }^{3}$, Rodrigo Garófallo Garcia ${ }^{3}$, Fabiana Ribeiro Caldara ${ }^{3}$, Grace Alessandra de Araujo Baldo $^{4}$, Edivaldo Antônio Garcia ${ }^{2}$, Andréa de Britto Molino ${ }^{5}$}

\footnotetext{
1 Universidade Estadual de Maringá, Programa de Pós-Graduação em Zootecnia, Maringá, PR, Brazil.

2 Universidade Estadual Paulista "Júlio de Mesquita Filho", Faculdade de Medicina Veterinária e Zootecnia, Departamento de Produção Animal, Botucatu, SP, Brazil.

${ }^{3}$ Universidade Federal da Grande Dourados, Faculdade de Ciências Agrárias, Dourados, MS, Brazil.

${ }^{4}$ Universidade Estadual Paulista "Júlio de Mesquita Filho", Faculdade de Medicina Veterinária e Zootecnia, Programa de Pós-Graduação em Zootecnia, Botucatu, SP, Brazil.

${ }^{5}$ Universidade de São Paulo, Faculdade de Medicina Veterinária e Zootecnia, Pirassununga, SP, Brazil.
}

\begin{abstract}
This study aimed to evaluate the relationship between the steadiness of broilers during the stance phase of locomotion, and the primary disorders of the locomotor system and gait. The experimental design was completely randomized, in a factorial arrangement $(2 \times 2+32)$, indicating two sexes and two genetic commercial strains, with five replications of 53 broilers each, and 32 (16 males and 16 females) indigenous chickens. Gait score and valgus and varus condition were assessed. Pictures of the birds were taken and evaluated. The broiler body was considered a spherical shape, and the centroid was calculated. From the geometric center of the body, a line was drawn perpendicularly to the sphere radius that formed an angle (ANG) with the other vertical line drawn from the centroid to the ground. The angle projected onto the ground was analyzed, and the body steadiness (EC) was estimated. At the 42nd day of growth, broilers were weighed to assess the body weight, the breast weight after slaughter, and the percentage of the breast (PB). Femoral degeneration, tibial dyschondroplasia, spondylolisthesis, and footpad dermatitis were evaluated. Fast-growing broilers presented a high prevalence of locomotor issues. The PB was not affected by sex or genetic strain. Males showed better ANG than the females, regardless of the genetic strain. More balanced EC was found in commercial broilers when compared with the indigenous chicken that stood slightly towards the back during the stance phase. A medium (in males) to high (in females) association between EC and ANG was found amongst broilers from the commercial strains in both males and females. The broilers from commercial strains presented more locomotor issues than the indigenous chicken. Commercial broiler strains show less locomotor soundness than indigenous chickens.
\end{abstract}

Key Words: bone pathology, postural balance, welfare

\section{Introduction}

The rapid weight gain and fast muscle growth due to intense genetic selection for additional breast muscle (pectoral hypertrophy) in broiler (Gallus domesticus) commercial strains affect the body balance of birds (Julian, 2005; Angel, 2007). Fast growing broilers tend to become lame and bow forward (Almeida Paz et al., 2010). As a consequence of this unstable equilibrium condition, the angle from the center of the body mass toward the ground tends to become wider than normal, affecting the gait and deteriorating the welfare (Bessei, 2006; Caplen et al., 2012).

Received January 25, 2016 and accepted May 6, 2016. Corresponding author: ibiarapaz@gmail.com http://dx.doi.org/10.1590/S1806-92902016000700003

Copyright (c) 2016 Sociedade Brasileira de Zootecnia. This is an Open Access article distributed under the terms of the Creative Commons Attribution License (http://creativecommons.org/licenses/by/4.0/), which permits unrestricted use, distribution, and reproduction in any medium, provided the original work is properly cited.
Brazilian indigenous chickens (Gallus gallus domesticus) are being re-introduced to the market. The birds are reared in a free-range system with more appropriate welfare than those from commercial strains (Sundrum, 2001); they have access to perches and paddocks with grass, which allows these birds to express their natural behavior. The meat from these birds meets a market niche.

Locomotor issues in commercial flocks remain a concern for the poultry industry in Brazil. The field evaluation and welfare audit are based mostly on the gait scoring technique (Kestin et al., 1992). However, the gait score method lacks in assessing the postural characteristics of the birds. Photometry is a methodology used to evaluate postural distress in humans, allowing the record of visual assessments (Mizuno et al., 2001; Rea et al., 2004). Photometry is a non-invasive and simple method that could be applied in evaluating the steadiness of broilers. Most methodologies used in human postural analysis require the use of lateral pictures of the subject, which can be adapted for the application in animals or birds (Chandler et al., 1990). 
This study aimed to compare the posture of broilers during the stance phase of locomotion, using the angle from the center of the body mass toward the ground, relating the variable to the bird gait score and other conditions associated with locomotion disorders. Commercial broilers were compared with indigenous chicken that did not undergo genetic selection on scientific basis, for production characteristics.

\section{Material and Methods}

The study was carried out in Dourados, Brazil (54 $11^{\circ} 6^{\prime \prime} \mathrm{W}$ longitude and $23^{\circ} 28^{\prime} 26^{\prime \prime} \mathrm{S}$ latitude) and approved by the Ethics Committee of Universidade Federal da Grande Dourados (case no. 009/2012).

A total of 1060 one-day-old broiler chicks from two commercial genetic strains $\left(\mathrm{Cobb}^{\circledR} 500\right.$ and $\mathrm{Ross}^{\circledR}$ 308) and 32 indigenous chickens were used in the experiment. The commercial strain broilers were separated by sex and randomly distributed into 20 pens with a flock density of $11.77 \mathrm{bird} \mathrm{m}^{-2}$, while the indigenous chickens were reared apart in another experimental field. The indigenous, or free-range chicken, is a crossbred between Red Junglefowl and mixed exotic domestic breed, usually reared in family agriculture, with a poor degree of genetic selection for production characteristics. The broilers from the commercial strains were raised inside an East-West solar oriented broiler house with tube feeders and drinkers; adequate feed and water were available ad libitum. The indigenous chickens were reared in a free-range system and also received the supplementary feed.

The broiler biomechanical and physical characteristics assessed inside the house were the gait score (GS) and the valgus (VAL) and varus (VAR) angular deformities. Lateral pictures of the birds were taken, and the body was assumed as a partial sphere. The centroid of the sphere was measured. From the geometric center of the body mass, a line was drawn perpendicularly to the sphere radius that formed an angle (ANG) with the other vertical line drawn from the centroid to the ground. The angle projected onto the ground was analyzed, and the body steadiness (EC) was evaluated.

During the 42nd day of growth, the commercial strain broilers were weighed to determine the body weight (BW), and after slaughter, the breast weight (BEW) and percentage of the breast $(\mathrm{PB})$ were assessed. The presence of femoral degeneration (FD), tibial dyschondroplasia (TD), spondylolisthesis (SPO), and footpad dermatitis (POD) were also evaluated. The same procedure was applied to the indigenous chickens.
The gait scoring was carried on all broilers on the 40th day of grow-out. Birds were stimulated to walk $1 \mathrm{~m}$ distance on a flat surface with rice husks, simulating the litter. The gait score was based on the following scale: $0=$ birds walking 10 steps or more in 1 linear meter in the normal way; 1 = the bird moves quickly, but a little deficiency is noted; 2 = the bird movements are fast, but high deficiency is observed while the bird walks; $3=$ the bird has severe difficulties during walking; $4=$ bird hardly walks and sometimes use the wings to improve walking; and $5=$ the bird either does not walk, or, almost immediate sits after the attempt of walking (Kestin et al., 1992).

After gait scoring, VAL and VAR were assessed using 30 broilers for each treatment in the commercial strains, and 32 of the indigenous chickens, as suggested by Leterrier and Nys (1992). The angle between the middle finger and the tibia of both right and left legs was measured using a caliper rule and a protractor. When the angle was higher than $10^{\circ}$ positive, it was characterized as VAL, and when this angle was greater than $10^{\circ}$ negative, it was marked as VAR. The footpad dermatitis was analyzed simultaneously, and scores were assigned from 0 to 2 (varying from good to poor).

The lateral pictures were taken using the same birds which were used for assessing VAL and VAR. Broilers were standing at $1 \mathrm{~m}$ distance from the tripod (height of $15 \mathrm{~cm}$ ) with the camera, and ANG and EC were measured from the picture (Chandler and Hemami, 2007). The bird was considered equivalent to a spherical cap (Figure 1). The centroid was calculated, and the center of symmetry

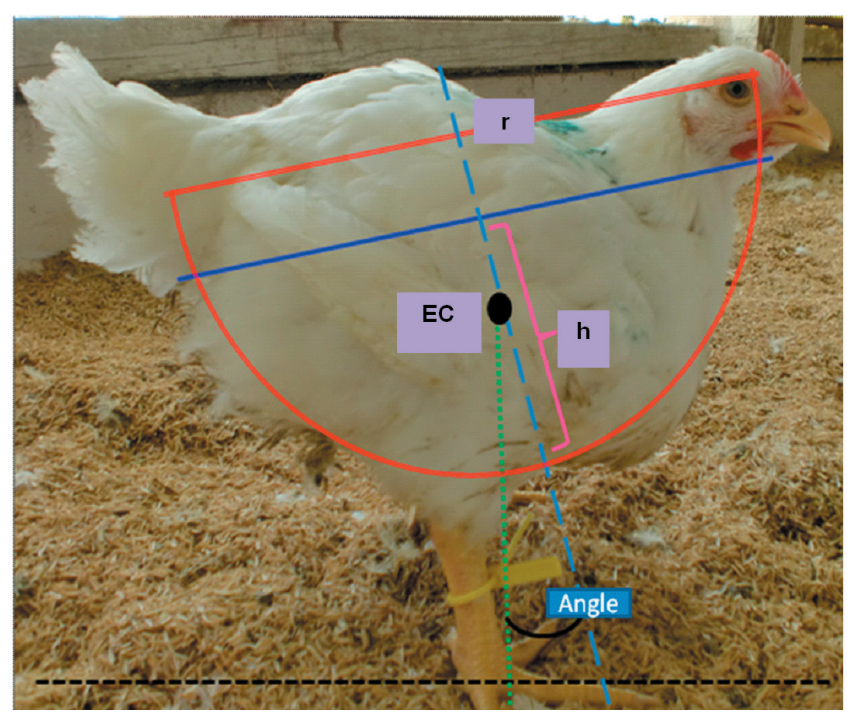

EC - equilibrium position (body steadiness on the gravity center); $r$-radius of the sphere; $\mathrm{h}$ - internal shaft.

Figure 1 - Assessment of broiler equilibrium condition and posture angle. 
was found. Using the equilibrium condition and the posture angle during the stance phase, the birds posture was obtained. The sphere radius was measured, and this value was constant for all analyzed images, as the birds had similar weight and shape. A parallel line to the sphere radius was drawn taking the cloacal basis at one end and the wattle at the other end. The difference between the cap sphere radius and the parallel line to the shaft of the cap was calculated as a function of the bird size. The equilibrium position (EC) was then calculated (Equation 1).

$$
E C=3 / 4\left(\frac{2(r-h)^{2}}{3(r-h)}\right)
$$

in which $\mathrm{EC}=$ equilibrium position (body steadiness on the gravity center); $r=$ the radius of the sphere; and $h=$ the internal shaft.

In the next step, a parallel line to the ground was drawn going through the bird footpad, which intersected the perpendicular line drawn from the mass centroid. The EC was set at the intersection of the vertical line and the line perpendicular to the sphere radius. The EC was scored based on the angle the body makes with the ground (Table 1). From the intersection of the spherical cap symmetry axis (at $90^{\circ}$ ) and the vertical line from the EC, the broiler ANG was estimated using a protractor. The angle difference found between the symmetry axes was calculated. In those birds which could not walk properly with high gait score, the ANG was assumed $0^{\circ}$.

Birds were anesthetized and euthanized by a jugular incision at 42 days of grow-out. The percentage of the breast related to the carcass was measured as the difference in weight between the cuts.

The femoral degeneration (FD) analysis was based on the integrity of the head of the femur in both left and right legs, and scores were given from 0 (head of the femur and cartilage without injuries) to 2 (femur totally injured).

For the assessment of TD, the thickness of the tibia cartilage growth was measured through an incision in both left and right tibias of each broiler to determine the growth

Table 1 - Score definition depending on where the calculated vertical line perpendicular to the ground touches the footpad of the birds

\begin{tabular}{ll}
\hline Score & \multicolumn{1}{c}{ Definition } \\
\hline 1 & The vertical line was positioned behind the footpad, and it \\
corresponds to a straight posture towards the back. \\
2 & The vertical line was positioned inside the footpad. \\
3 & $\begin{array}{l}\text { The vertical line was positioned in front of the footpad } \\
\text { denoting a posture towards the front. }\end{array}$ \\
4 & $\begin{array}{l}\text { The vertical line was positioned outside the footpad, and the } \\
\text { bird could barely stand up. }\end{array}$
\end{tabular}

plate. The given scores were from 0 to 2 as a function of the abnormal local cartilage (Almeida Paz et al., 2005).

The SPO investigation was performed by sawing the spine sagittally to visualize macroscopically the bird cervical spine between the 6th and the 7th vertebrae (Wise, 1970; Riddell, 1973; Wise, 1973). When the vertebrae were found in their normal axis and without compressing the bone marrow, the given score was 0 (no issue in the cervical spine). However, when the vertebrae compressed the bone marrow causing locomotor distress, the given score was 1 (presence of SPO).

The experimental design was completely randomized in a factorial arrangement $(2 \times 2+32)$ organized in two sexes and two genetic strains (A and B), with five replications of 53 birds each. A total 16 males and 16 females of indigenous chickens were added to the experiment (Table 2).

Analysis of variance was applied to the results. Data related to locomotor issues (GS, VAL and VAR, POD, ANG, EC, FD, TD, and SPO) were tested using the Kruskal-Wallis test for checking the normality of the residue. The Levene test was applied for testing the homogeneity of the variance. Data from live weight and breast weight were tested with ANOVA, and means were compared using Tukey's test. All statistical analyses were performed at a confidence level of 95\%. Data were processed using SAS (Statistical Analysis System, version 9.2.) statistical software.

\section{Results and Discussion}

No interaction $(\mathrm{P}>0.05)$ was found between sex and genetic strain; therefore, all studied characteristics were discussed separately (GS, SPO, FD, TD, ANG, EC, VAL, and VAR). The variables ANG and EC were affected by the bird sex. The genetic strain of the birds affected the variables GS, POD, SPO, FD, and EC. Treatments did not influence bone deformities VAL, VAR, or TD (Table 3).

The two commercial strains and the indigenous chicken had GS incidence of 1 to 5 in less than $30 \%$ of the birds (Table 4), and similar values for valgus (VAL) and varus deformities, which was also found on commercial farms in the European Union and the United States (Sorensen et al.,

Table 2 - Description of the experimental treatments

\begin{tabular}{lcc}
\hline Treatment & Commercial broiler strain & Sex \\
\hline T1 & A & Male \\
T2 & A & Female \\
T3 & B & Male \\
T4 & B & Female \\
T5 & Indigenous & Male \\
T6 & Indigenous & Female \\
\hline
\end{tabular}

R. Bras. Zootec., 45(7):372-379, 2016 
2000; Grandin, 2007). Although visually there is a high percentage of broilers commonly walking on commercial farms, this might not mean that there are only sound birds in the flock (Fernandes et al., 2012).

The difference found between the commercial strains and the indigenous chicken might be assigned to various factors, the most critical of which are the weight distribution and the way broilers gain weight during the grow-out period. Mean values of weight found were of $2.610 \mathrm{~g}$ for the broilers from commercial strains, and $1.670 \mathrm{~g}$ for the indigenous chickens. This difference in body weight might interfere with the posture during locomotion and in the stance phase, compromising the way of walking. The marked development of the pectoralis major of the current broiler moved its gravity center (Weeks et al., 2000), negatively influencing the bird equilibrium condition and modifying its body posture, which may aggravate back problems and compromise walking. One of the hypotheses is that bone development in these animals is not sufficiently adequate to support their weight. Indigenous chickens that are raised in a free-range system have a slower weight gain with consistent bone growth.

Comparing the gait of commercial strain and jungle fowl, Caplen et al. (2012) found that broiler genetic strains present an unbalanced body due to the intense genetic selection for additional breast muscle (pectoral hypertrophy). Fast-growth birds develop compensatory gait adaptations to minimize energy expenditure that

Table 3 - Levels of confidence for the effects of non-parametric variables

\begin{tabular}{|c|c|c|}
\hline \multirow{2}{*}{ Trait } & Genetic strain & Sex \\
\hline & \multicolumn{2}{|c|}{ P-value } \\
\hline Gait score & $<0.0001$ & ns \\
\hline Pododermatitis & 0.0300 & ns \\
\hline Spondylolisthesis & 0.0399 & ns \\
\hline Femoral degeneration & 0.0001 & ns \\
\hline Tibial dyschondroplasia & ns & ns \\
\hline Angulation & ns & 0.0047 \\
\hline Equilibrium condition & 0.0003 & 0.0200 \\
\hline Valgus & ns & ns \\
\hline Varus & ns & ns \\
\hline
\end{tabular}

ns - not significant $(\mathrm{P}>0.05)$

Table 4 - Frequency of gait score in broilers from commercial genetic strains and indigenous chicken

\begin{tabular}{lcccccc}
\hline \multirow{2}{*}{ Genetic strain } & 0 & 1 & 2 & 3 & 4 & 5 \\
\cline { 2 - 7 } & $77.0 \mathrm{a}$ & $10.7 \mathrm{a}$ & $5.0 \mathrm{a}$ & $3.6 \mathrm{a}$ & $2.5 \mathrm{a}$ & $1.2 \mathrm{a}$ \\
$\mathrm{A}$ & $82.4 \mathrm{a}$ & $7.7 \mathrm{a}$ & $4.8 \mathrm{a}$ & $1.7 \mathrm{a}$ & $2.9 \mathrm{a}$ & $0.6 \mathrm{a}$ \\
$\mathrm{B}$ & $100.0 \mathrm{~b}$ & $0.0 \mathrm{~b}$ & $0.0 \mathrm{~b}$ & $0.0 \mathrm{~b}$ & $0.0 \mathrm{~b}$ & $0.0 \mathrm{~b}$ \\
\hline
\end{tabular}

Means followed by different letters in the column differ by the Kruskal-Wallis test $(\mathrm{P} \leq 0.05)$.

Commercial broiler strain A - Cobb ${ }^{\circledR} 500$; Commercial broiler strain B - Ross ${ }^{\circledR} 308$. triggers high-lameness prevalence within commercial flocks. Broilers do not walk much inside the house during the grow-out period, since hunger and thirst are not the primary stimuli for birds to move (Bokkers et al., 2006). On commercial broiler farms, feeders and drinkers are placed close to the birds, and consequently, these birds need to walk less than the indigenous chickens reared in free-range systems (Ganabadi et al., 2009).

Neither sex nor genetic strain $(\mathrm{P}>0.05)$ had an effect on the angular leg deformities. A total of $19.5 \%$ of broilers had VAL, and $7.6 \%$ presented VAR. The total percentage of angular deformities was lower than those found in the current literature (Fernandes et al., 2012). Almeida Paz et al. (2010) indicated that nearly $32 \%$ of commercial broilers had angular leg deformities; however, no difference was found between sex and genetic strains. The percentage of birds with lateral deviation VAL was higher than with VAR, which is commonly found in the literature on bone deformities (Julian, 1984; Leterrier and Nys, 1992; Hocking, 2014).

The indigenous chickens showed less footpad lesion than the broilers from the commercial strains (Table 5). The result could be credited to the rearing system. The increase in the number of footpad lesions is related to high-flock density and the fast growth of the birds, and it may be the result of inappropriate litter management (Dozier III et al., 2005). Indigenous chickens are usually reared in free-range systems, and they walk on different types of abrasive grounds that might result in a denser footpad. In the present study, only two indigenous chicken males and two females had footpad lesions. The broilers from the commercial genetic strains reared on litter showed more

Table 5 - Frequency (\%) of leg disorders (pododermatitis, spondylolisthesis, femoral degeneration, and tibial dyschondroplasia) in broilers from commercial genetic strains and the indigenous chicken

\begin{tabular}{lcccc}
\hline \multirow{2}{*}{ Leg disorder } & Score & \multicolumn{3}{c}{ Genetic strain } \\
\cline { 2 - 5 } & & $\mathrm{A}$ & $\mathrm{B}$ & Indigenous chicken \\
\hline POD & 0 & $48.3 \mathrm{~b}$ & $45.0 \mathrm{~b}$ & $93.8 \mathrm{a}$ \\
& 1 & $35.0 \mathrm{~b}$ & $33.3 \mathrm{~b}$ & $6.2 \mathrm{a}$ \\
& 2 & $16.7 \mathrm{~b}$ & $21.7 \mathrm{~b}$ & $0.0 \mathrm{a}$ \\
SPO & 0 & $75.0 \mathrm{~b}$ & $85 \mathrm{~b}$ & $100.0 \mathrm{a}$ \\
& 1 & $25.0 \mathrm{~b}$ & $15 \mathrm{~b}$ & $0.0 \mathrm{a}$ \\
FD & 0 & $45.0 \mathrm{~b}$ & $43.3 \mathrm{~b}$ & $93.7 \mathrm{a}$ \\
& 1 & $50.0 \mathrm{~b}$ & $51.7 \mathrm{~b}$ & $6.3 \mathrm{a}$ \\
& 2 & $5.0 \mathrm{~b}$ & $5.0 \mathrm{~b}$ & $0.0 \mathrm{a}$ \\
TD & 0 & 95.0 & 96.6 & 100.0 \\
& 1 & 3.3 & 1.7 & 0.0 \\
& 2 & 1.7 & 1.7 & 0.0
\end{tabular}

POD - pododermatitis; SPO - spondylolisthesis; FD - femoral degeneration; TD tibial dyschondroplasia.

Means followed by different letters in a row differ by the Kruskal-Wallis test $(\mathrm{P}<0.05)$. Commercial broiler strain A - Cobb ${ }^{\circledR} 500$; Commercial broiler strain B - Ross ${ }^{\circledR} 308$. 
footpad lesions than the indigenous chickens, probably as a result of the litter fermentation and consequent increase in surface temperature (Garcia et al., 2012). Dawkins et al. (2004) described the prevalence footpad dermatitis in birds with rapid growth rate, which explained the high incidence of POD found in the present study in broilers from commercial genetic strains.

The frequency of occurrence of SPO in broilers of the Cobb $^{\circledR} 500$ and Ross $^{\circledR} 308$ strains differed from that found in the indigenous chickens $(\mathrm{P} \leq 0.05)$, and the birds from the commercial strains were the most affected. Wise (1970) found similar results indicating that SPO might be related to a genetic factor. However, reasons for this disease are multifactorial and not yet clear. Results by other authors suggest that age, sex, and management might influence the occurrence of SPO (Riddell, 1973; Wise, 1973). Almeida Paz et al. (2010) found the incidence of SPO related to management and litter, regardless of sex and genetic strain. The rate of this anomaly in the present study was higher than other findings in the current literature when this pathology reaches nearly $2 \%$ of commercial flocks (Osbaldiston et al., 1967; Wise, 1970).

The difference found in FD results appears to be related to the low occurrence of this condition found in indigenous chickens. Fernandes et al. (2012) indicated that $72 \%$ of broilers in commercial flocks had sound femur. The results of these authors are similar to the outcome of the present study including the commercial strains A and B. Almeida Paz et al. (2010) found a lower frequency of occurrence varying from 15 to $19 \%$ of broilers with FD in the commercial flock. No difference between sex or genetic strain $(\mathrm{P}>0.05)$ was identified. The mineral composition of the bones and cartilage were probably affected by the genetic selection for broiler leading to the presence of the FD condition (Schmidt et al., 2009; Almeida Paz et al., 2009; Hocking, 2014). Since a histological evaluation region affected by FD condition is shown with angiogenesis and changes in the integrity and arrangement of the cells, in many cases no presence of joint cartilage is observed in the femur head (Almeida Paz et al., 2009).

Indigenous chickens walked sounder than broilers from the commercial strains, probably due to the higher percentage of muscle found in commercial broilers. Bone anomalies were also present in rapid growth broilers, as they are more susceptible to tissue hypoxia (Angel, 2007). The frequency of TD occurrence did not differ in sex or genetic strain $(\mathrm{P}>0.05)$ in the present study, agreeing with other findings in the literature (Almeida Paz et al., 2010; Fernandes et al., 2012). Previous research reported TD in $83 \%$ of broilers in commercial flocks (Cruickshank and
Sim, 1986; Almeida Paz et al., 2005). The decrease in the incidence of this pathology might be a result of the genetic improvement (Tickle et al., 2014), whereas the breeding was used to obtain broilers resistant to this anomaly. Thus, the TD incidence decreased from about $83 \%$ to $5 \%$ (Fernandes et al., 2012) in 20 to 15 years. In the present study, the frequency of TD incidence did not differ amongst all birds, although it was expected that the presence of TD in rustic birds would be different from that in commercial broilers. According to Praul et al. (2000), TD is usually caused by rapid growth, and heavier birds are more likely to present the disease.

The angle projected onto the ground was affected only by the sex $(\mathrm{P} \leq 0.05)$, independent of the genetic strain (Figure 2). Male broilers showed better ANG than females, which showed a higher incidence of zero ANG, as more females remained laying on the litter. As male broilers are heavier than the females, the males were expected to present more appropriate ANG. Since the percentages of breast meat in both sexes did not differ, the difference in ANG might not be related to the broiler sex. Angel (2007) did not find a difference in bone mineralization and growth in the first weeks of the broiler growth; however, the male birds presented higher skeletal strength and bone resistance than the females.

Results for equilibrium condition (EC) were not affected by genetic strain or sex (Figure 3). Ross ${ }^{\circledR} 308$ broilers showed better EC (score 2) in both males and females than the other tested birds. Cobb $^{\circledR} 500$ broilers stayed more prostrated than the others most of the time, while the indigenous chickens presented a higher number of score 1 than the other studied birds. This incidence was probably because the indigenous chickens have longer bones than the other genetic strains studied. $\mathrm{Cobb}^{\circledR} 500$ female broilers had scores 3 and 4 . None of the studied

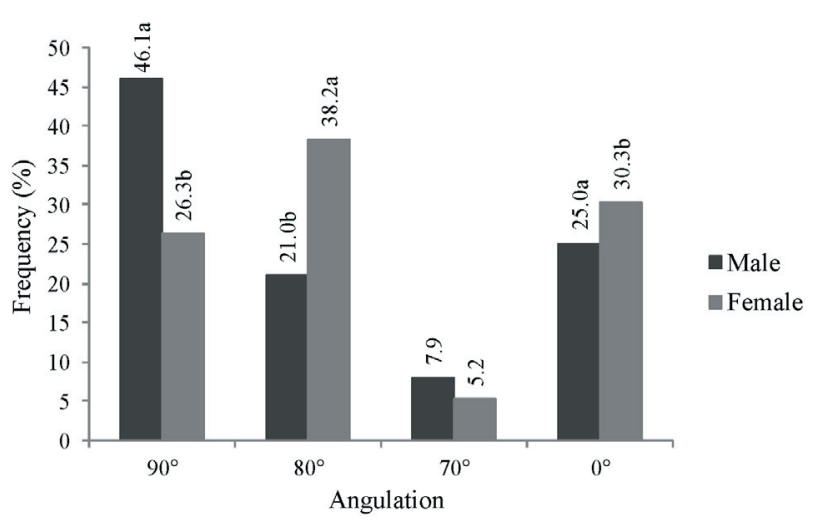

Figure 2 - Frequency of angulation found in the male and female broilers of commercial genetic strains $\left(\mathrm{Cobb}^{\circledR} 500\right.$ and $\operatorname{Ross}^{\circledR}$ 308). 
birds showed an ideal balance during the stance phase. Female Ross $^{\circledR} 308$ presented $60 \%$ of score 2 (perfect balance) and $0 \%$ of prostrated birds. These results might be explained by the weight of birds (Table 6), as Cobb $^{\circledR} 500$ strain female broilers had an intermediate weight between

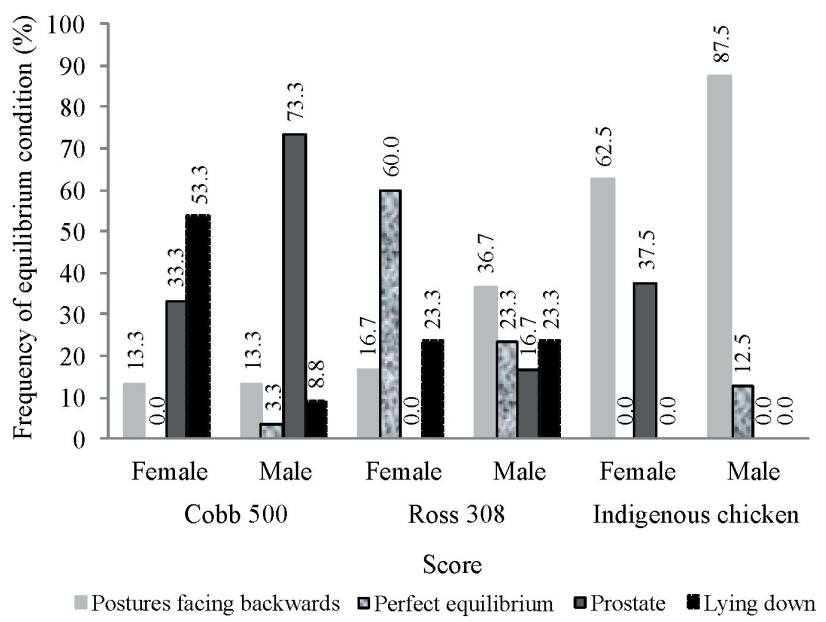

Figure 3 - Frequency of the equilibrium condition in the studied commercial genetic strains $\left(\mathrm{Cobb}^{\circledR} 500\right.$ and $\left.\operatorname{Ross}^{\circledR} 308\right)$ and indigenous chicken.

Table 6 - Means of body weights ( $\mathrm{g}$ ) and breast percentage of broiler strains and indigenous chicken

\begin{tabular}{lccc}
\hline Genetic strain & Sex & $\begin{array}{c}\text { Body weight } \\
(\mathrm{g})\end{array}$ & $\begin{array}{c}\text { Percentage of breast } \\
(\%)\end{array}$ \\
\hline $\mathrm{A}$ & Male & $2825 \mathrm{a}$ & $40.3 \mathrm{a}$ \\
& Female & $2535 \mathrm{ab}$ & $40.1 \mathrm{a}$ \\
$\mathrm{B}$ & Male & $2754 \mathrm{a}$ & $41.3 \mathrm{a}$ \\
& Female & $2329 \mathrm{~b}$ & $40.8 \mathrm{a}$ \\
Indigenous chicken & Male & $1810 \mathrm{c}$ & $38.9 \mathrm{a}$ \\
& Female & $1530 \mathrm{c}$ & $38.2 \mathrm{a}$ \\
$\mathrm{CV}(\%)$ & & 21.15 & 12.30 \\
\hline
\end{tabular}

$\mathrm{CV}$ - coefficient of variation (\%).

Means followed by different letters in the column differ by Tukey's test $(\mathrm{P} \leq 0.05)$. Commercial broiler strain A - Cobb ${ }^{\circledR} 500$; Commercial broiler strain B - Ross ${ }^{\circledR} 308$. the male from commercial genetic strains and the female from $\operatorname{Ross}^{\circledR} 308$, and these birds presented thinner bones when compared with males (Tickle et al., 2014). Male and female indigenous chicken showed a high incidence of score 1 , and $37.5 \%$ of females were prostrated at some point during the research. This methodology of observing EC related to their stance behavior might not be sufficient to estimate bird welfare. It has been reported that birds with little genetic selection pressure have a more upright posture, while modern broilers present a larger pectoral muscle mass and increased meat yield, tending to bow forward during the stance phase (Havenstein et al., 2003; Schmidt et al., 2009; Caplen et al., 2012).

When correlating the locomotor issues ANG, EC, and GS from male and female broilers (Table 7), it was found that GS presented a low correlation with TD (0.19), SPO (0.35), VAL (0.27), and POD (-0.23). Some authors have indicated a low correlation between GS and locomotor issues in broilers (Sanotra et al., 2001; Almeida Paz et al., 2010; Fernandes et al., 2012). The gait score method proposed by Kestin et al. (1992) estimates the welfare of broilers during walking. The gait score might not be sufficient to predict bone anomalies (Garner et al., 2002; Fernandes et al., 2012) due to the subjectivity and the difficulties of the standardization of the technique.

The high incidence of GS (from 1 to 5) varies with ANG (-0.28) and, consequently, EC (-0.27) is affected to induce a proper balance and to reduce the bird discomfort. Posture tends to change, and the leg becomes curved (GS $\times$ VAL - 0.27). As ANG changes, the bird tends to move inclined forwards, influencing the rise of SPO (-0.31).

Results of broiler correlation with BW (-0.20), BEW $(-0.37)$, and GS $(-0.28)$ indicate that heavier birds tend to move slower than lighter birds (Paxton et al., 2013). Footpad

Table 7 - Correlations between evaluated traits: body weight and breast, locomotor problems, angulation, and equilibrium condition in commercial broiler genetic strains and indigenous chicken

\begin{tabular}{|c|c|c|c|c|c|c|c|c|c|c|c|}
\hline & BW & BEW & GS & FD & TD & SPO & VAL & VAR & POD & ANG & $\mathrm{EC}$ \\
\hline BW & 1.000 & $0.86^{*}$ & - & $0.24 *$ & - & - & - & - & - & $0.27 *$ & $0.27^{*}$ \\
\hline BEW & & 1.00 & - & $0.25^{*}$ & - & - & - & - & - & $0.30 *$ & $0.30^{*}$ \\
\hline GS & & & 1.000 & - & $0.19 * *$ & $0.35^{*}$ & $0.27 *$ & - & $-0.23 * *$ & $-0.28 *$ & -0.27 \\
\hline FD & & & & 1.00 & - & - & - & - & - & - & - \\
\hline TD & & & & & 1.00 & - & - & - & - & - & - \\
\hline SPO & & & & & & 1.00 & - & - & - & $-0.31 *$ & -0.31 * \\
\hline VAL & & & & & & & 1.00 & - & $-0.26 * *$ & - & - \\
\hline VAR & & & & & & & & 1.00 & - & - & - \\
\hline POD & & & & & & & & & 1.00 & - & - \\
\hline ANG & & & & & & & & & & 1.00 & $0.53 *$ \\
\hline EC & & & & & & & & & & & 1.00 \\
\hline
\end{tabular}

BW - body weight; BEW - breast weight; GS - gait score; FD - femoral degeneration; TD - tibial dyschondroplasia; SPO - spondylolisthesis; VAL - valgus angular deformity; VAR - varus angular deformity ; POD - footpad dermatitis; ANG - angulation; EC - equilibrium condition; ns - not significant.

* Spearman Correlations $(\mathrm{P} \leq 0.01)$; ** Spearman Correlations $(\mathrm{P} \leq 0.05)$. 
lesions $(-0.28)$ and EC $(-0.28)$ presented a low association with the broilers of genetic strains. Body weight (BW) and BEW were correlated with ANG and EC, confirming the trend that a weight increase is detrimental to the bird posture. As weight values were similar for all birds, low correlations were found between breast meat weight and live weight, and ANG and EC.

With the need to provide meat to humans, genetic selection in broilers has adopted the trend to increase conversion rate and rapid growth (Pym, 2005; Bessei, 2006). However, this trend might not be the ideal towards bird welfare, as it causes an adverse impact on their locomotion (Kestin et al., 1992; Tickle et al., 2014). Indigenous chicken presented lower muscle conformation and slow bone development (Ganabadi et al., 2009) and, therefore, these birds appear to be sounder than commercial genetic strain broilers.

\section{Conclusions}

Gait score, posture angle, and equilibrium condition show a moderate to strong association; and the determination of these variables, especially the equilibrium condition, might be a suitable method for estimating locomotor abilities of broilers. The way broilers walk appears to be more related to body posture than to bone pathologies.

Commercial broiler strains show less locomotor soundness than indigenous chickens.

\section{Acknowledgments}

The authors wish to thank CAPES for supporting this research.

\section{References}

Almeida Paz, I. C. L.; Mendes, A. A. and Takita T. S. 2005. Comparison of techniques for tibial dyschondroplasia assessment in broiler chickens. Brazilian Journal of Poultry Science 7:27-31.

Almeida Paz, I. C. L.; Mendes, A. A.; Martins, M. R. F. B.; Fernandes, B. C. S.; Almeida, I. C. L.; Milbradt, E. L.; Balog, A. and Komiyama, C. M. 2009. Follow-up of the development of femoral degeneration lesions in broilers. International Journal of Morphology 27:571-575.

Almeida Paz, I. C. L.; Garcia, R. G.; Bernardi, R.; Nääs, I. A.; Caldara, F. R.; Freitas, L. W.; Seno, L. O.; Ferreira, V. M. O. S.; Pereira, F. D. and Cavichiolo F. 2010. Selecting appropriate bedding to reduce locomotion problems in broilers. Brazilian Journal Poultry Science 12:189-195.

Angel, R. 2007. Metabolic disorders: limitations to growth of and mineral deposition into the broiler skeleton after hatch and potential implications for leg problems. Journal Applied Poultry Research 16:138-149.

Bessei, W. 2006. Welfare of broilers: a review. World Poultry Science Journal 62:455-466.
Bokkers, E. A. M.; Zimmerman, P. H.; Rodenburg, T. B. and Koene, P. 2006. Walking behaviour of heavy and light broilers in an operant runway test with varying durations of feed deprivation and feed access. Applied Animal Behaviour Science 108:129-142.

Caplen, G.; Hothersall, B. J.; Murrell, C.; Nicol, C. J. A.; WatermanPearson, E.; Weeks, C. A. and Colborne R. 2012. Kinematic analysis quantifies gait abnormalities associated with lameness in broiler chickens and identifies evolutionary gait differences. PLoS ONE 7:e40800.

Chandler, J. M.; Duncan, P. W. and Studenski, S. A. 1990. Balance performance on the postural stress test: comparison of young adults, healthy, elderly, and fallers. Phys. Therapy 70:410-415.

Chandler, D. M. and Hemami, S. S. 2007. VSNR: a wavelet-based visual signal-to-noise ratio for natural images. IEEE Transactions Image Processing 16:2284-2298.

Cruickshank J. and Sim, J. 1986. Morphometric and radiographic characterization of tibial bone of broiler chickens with twisted leg disorders. Avian Diseases 30:699-708.

Dawkins, M. S.; Donnelly, C. A. and Jones, T. A. 2004. Chicken welfare is influenced more by housing conditions than by stocking density. Nature 427:342-344.

Dozier III, W. A.; Thaxton, J. P.; Branton, S. L.; Morgan, G. W.; Miles, D. M.; Roush, W. B.; Lott, B. D. and Vizzier-Thaxton, Y. 2005. Stocking density effects on growth performance and processing yields of heavy broilers. Poultry Science 84:1332-1338.

Fernandes, B. C. S.; Martins, M. R. F. B.; Mendes, A. A.; Almeida Paz, I. C. L.; Komiyama, C. M. and Milbradt, E. L. 2012. Locomotion problems of broiler chickens and its relationship with the gait score. Revista Brasileira de Zootecnia 33:128-135.

Ganabadi, S.; Mutuviren, S.; Hilmi, M. A.; Babjee, S. M. A.; Yaakub, H. and Fakurazi, S. 2009. Carcass composition of jungle fowl in comparison with broilers and indigenous chicken. Asian Journal of Animal Sciences 3:13-17.

Garcia, R. G.; Almeida Paz, I. C. L.; Caldara, F. R.; Nääs, I. A.; Pereira, D.F. and Ferreira, V. M. O. S. 2012. Selecting the most adequate bedding material for broiler production in Brazil. Brazilian Journal Poultry Science 14:121-127.

Garner, J. P.; Falcone, C.; Wakenell, P.; Martin, M. and Mench, J. A. 2002. Reliability and validity of a modified gait scoring system and its use in assessing tibial dyschondroplasia in broilers. British Poultry Science 43:355-363.

Grandin, T. 2007. Poultry slaughter plant and farm audit: critical control points for bird welfare. Available at: $<$ http//www.grandin. com/poultry.audit.html $>$. Accessed on: Dec. 10, 2013.

Havenstein, G. B.; Ferket, P. R. and Qureshi, M. A. 2003. Carcass composition and yield of 1957 versus 2001 broilers when fed representative 1957 and 2001 broiler diets. Poultry Science 82:1509-1518.

Hocking, P. M. 2014. Unexpected consequences of genetic selection in broilers and turkeys: problems and solutions. British Poultry Science 55:1-12.

Julian, R. J. 1984. Valgus-varus deformity of the intertarsal joint in broiler chickens. The Canadian Veterinary Journal 25:254-258.

Julian, R. J. 2005. Production and growth related disorders and other metabolic diseases of poultry: A review. Veterinary Journal 169:350-369.

Kestin, S. C.; Knowles, T. G.; Tinch, A. E. and Gregory, N. G. 1992. Prevalence of leg weakness in broiler chickens and its relationship with genotype. Veterinary Records 131:190-194.

Leterrier C. and Nys, Y. 1992. Clinical anatomical differences in varus and valgus deformities of chick limbs suggest different aetio-pathogenesis. Avian Pathology 21:429-442.

Mizuno, Y.; Kumagai, M.; Mattessich, S. M.; Elias, J. J.; Ramrattan, N.; Cosgarea, A. J. and Chao E. Y. 2001. Q-angle influences tibiofemoral and patellofemoral kinematics. Journal of Orthopedic Research 19:834-840.

Osbaldiston, G. W. and Wise, D. R. 1967. Spondylolisthesis and leg weakness in the chicken - a common aetiology. Veterinary Record $80: 320-322$ 
Paxton, H.; Daley, M. A.; Corr, S. A. and Hutchinson, J. R. 2013. The gait dynamics of the modern broiler chicken: a cautionary tale of selective. The Journal of Experimental Biology 216:3237-3248.

Praul, C. A.; Ford, B. C.; Gay, C.; Pines, M. and Leach, R. M. 2000. Gene expression and tibial dyschondroplasia. Poultry Science 79:1009-1013.

Pym, R. A. E. 2005. Genetic aspects of food intake and food utilization efficiency for growth in chickens. p.153-162. In: Australian Poultry Science Symposium, 17. The World's Poultry Science Association, Sydney.

Rea, M.; Bullough, J.; Freyssinier-Nova J. and Bierman, A. 2004. A proposed unified system of photometry. Lighting Research and Technology 36:85-111.

Riddell, C. 1973. Studies on spondylolisthesis (kinky back) in broiler chickens. Avian Pathology 2:295-304.

Sanotra, G. S.; Lund, J. D. and Ersboll, A. K. 2001. Monitoring leg problems in broilers: a survey of commercial broiler production in Denmark. World Poultry Science Journal 57:55-69.
Schmidt, C. J.; Persia, M. E.; Feierstein, E.; Kingham, B. and Saylor, W. W. 2009. Comparison of a modern broiler line and a heritage line unselected since the 1950s. Poultry Science 88:2610-2619.

Sorensen, P.; Su, G. and Kestin, S. C. 2000. Effects of age and stocking density on leg weakness in broiler chickens. Poultry Science 79:864-870.

Sundrum, A. 2001. Organic livestock farming - A critical review. Livestock Production Science 67:207-215.

Tickle, P. G.; Paxton, H.; Rankin, J. W.; Hutchinson, J. R. and Codd, J. R. 2014. Anatomical and biomechanical traits of broiler chickens across ontogeny. Part I. Anatomy of the musculoskeletal respiratory apparatus and changes in organ size. PeerJ 2:e432 doi:10.7717/peerj.432.

Weeks, C. A.; Danbury, T. D.; Davies, H.C.; Hun, T. P.; Kestin, S. C. 2000. The behavior of broiler chickens and its modification by lameness. Applied Animal Behaviour Science 67:111-125.

Wise, D. R. 1970. Spondylolisthesis (kinky back) in broiler chickens. Research in Veterinary Science 2:447-451.

Wise, D. R. 1973. The incidence and aetiology of avian spondylolisthesis (kinky back). Research in Veterinary Science 14:1-10. 